\title{
SYNCHRONICITY OF VENTRICULAR CONTRACTION: OBSERVATIONS COMPARING HAMODYNAMIC EFFECTS OF ATRIAL AND VENTRICULAR PACING
}

\author{
BY \\ JOSEPH P. GILMORE, STANLEY J. SARNOFF, JERE H. MITCHELL, * \\ AND RONALD J. LINDEN†
}

From the Laboratory of Cardiovascular Physiology, National Heart Institute, Bethesda, Maryland, U.S.A.

Received September 12, 1962

In the course of earlier investigations it was noted that when the heart was paced by ventricular stimulation, mean left atrial pressure was higher for any given cardiac output, aortic pressure, and stroke work than when the atrium was paced at the same rate. Although the changes observed in those initial observations were not always striking, it was felt desirable to clarify the mechanisms by which they took place and to find what influenced their magnitude. Accordingly, a more systematic investigation was undertaken.

Two explanations were entertained that it was thought might account for the observed phenomena. The first was that, as suggested by Koch (1920) and Wiggers (1925), ventricular stimulation does not produce as well-organized a wave of ventricular depolarization as is the case when the impulse is normally propagated, and so results in a less synchronous ventricular contraction. Secondly, it was reasoned that if the ventricle had perchance been stimulated at such a rate and at such a time in the cardiac cycle that the paced ventricle and the spontaneously beating atrium were contracting simultaneously, the atrium would have been contracting against a closed atrio-ventricular valve, thus depriving the ventricle of that portion of its filling and the consequent influence on contraction which normally results from atrial systole (Sarnoff and Mitchell, 1961). The results of experiments designed to examine the validity of these two explanations over the whole range of ventricular function and to ascertain the effects of such changes on flow are the subject of this communication. A preliminary report on a portion of these data has been previously presented (Linden et al., 1959).

\section{METHODS}

Mongrel dogs of both sexes weighing 17.5 to $31.5 \mathrm{~kg}$. were anæsthetized with morphine, chloralose, and urethane. The chest was opened under intermittent positive pressure breathing and the appropriate cannulations made so as to be able to record continuously aortic blood flow and heart rate, as well as right atrial, left atrial, aortic, and pulmonary arterial pressures and left ventricular diastolic pressure. The techniques used were essentially the same as those described (Sarnoff $e$ t al., 1960a) with the following additions. After pericardiotomy, pacing electrodes were placed on the right or left atrium or both, on the right or left ventricle or both, and sometimes on all four chambers. Each cardiac electrode, as well as the indifferent electrode, was connected to a multiplexing switch so that the impulse could be applied to the atrium and then instantaneously changed from atrium to ventricle and back again as desired. No special effort was made to apply the ventricular electrode to any particular place on the ventricular myocardium although generally it was applied to the lateral wall of the ventricle near the atrioventricular sulcus rather than in the vicinity of the ventricular septum. The electrodes for atrial pacing were applied on or near the atrial appendage.

* Present address: Southwestern Medical School, Dallas, Texas.

$\dagger$ Present address: Department of Physiology, University of Leeds, England 
An impulse duration of from 3 to $5 \mathrm{~m} \mathrm{sec}$. obtained from a Grass impulse generator was used. The stimulus voltage was adjusted to a level just above that which would produce a response at each of the applied electrodes. Generally, the voltage that provided an effective stimulus at any one site also did so at each of the others. Care was taken to be certain that the electrodes were not in such a position as to transmit the stimulus to the ventricle via pericardial fluid when the stimulus was being applied to the atrium, and vice versa.

The impulse frequency applied to the heart was usually just at or above the spontaneous heart rate. It is important to note that it was then delicately adjusted to the rate that, when applied to the ventricle, gave the greatest steady state changes in the observed values when compared with the results of applying the same stimulus frequency to the atrium. Under these circumstances atrial systole occurred while the mitral valve was closed (see Fig. 5). Not infrequently, a cyclic reciprocating pattern of atrial and arterial pressures was encountered, as seen in Fig. 7: when this happened the rate was changed slightly in order to eliminate this cycling effect and produce steady state alterations in each of the values being recorded.

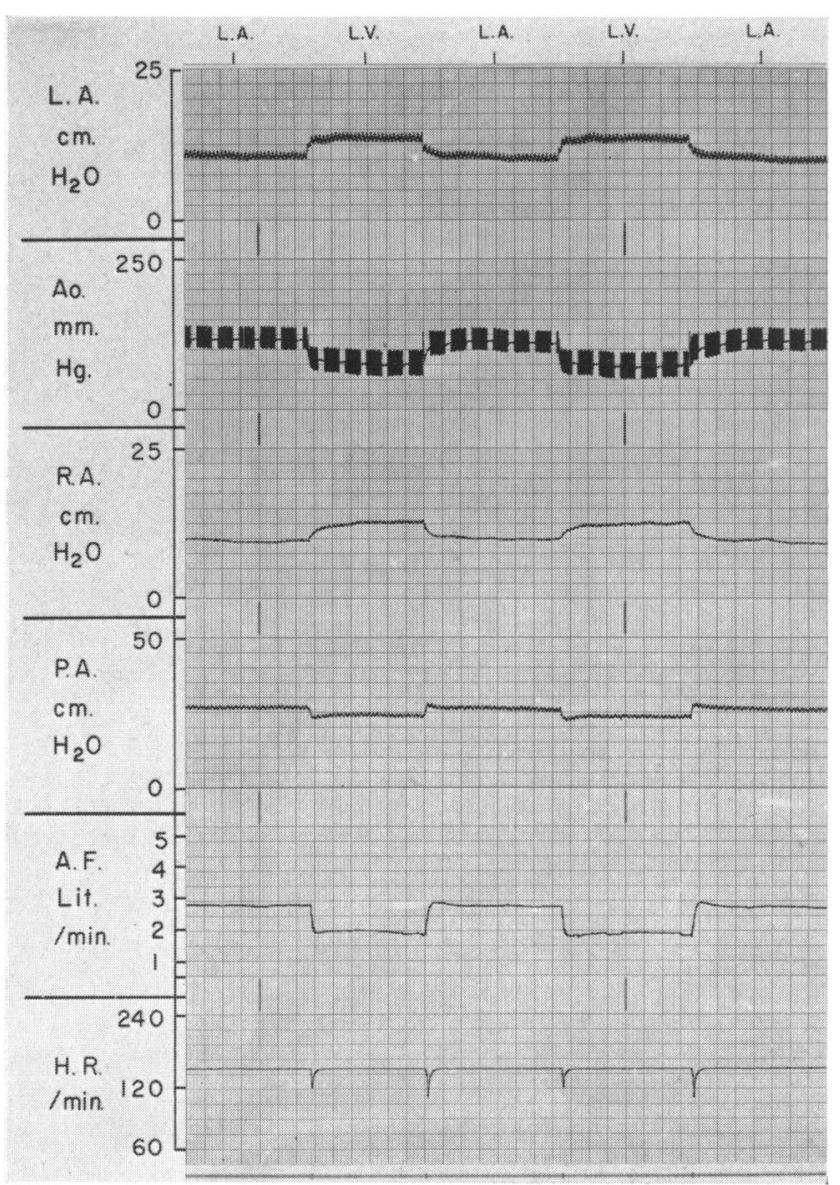

FIG. 1.-L.A. =mean left atrial pressure; Ao=aortic pressure (full pulse pressure alternating with electricity integrated mean pressure); R.A. =mean right atrial pressure; P.A. = mean pulmonary artery pressure; A.F.=aortic flow (cardiac output minus coronary flow); H.R. =heart rate. L.A. and L.V. at top of tracing indicate periods during which the left atrium or left ventricle were stimulated. Bilateral stellectomy and bilateral cervical vagotomy. Chart speed $=0.5 \mathrm{~mm}$. $/ \mathrm{sec}$.
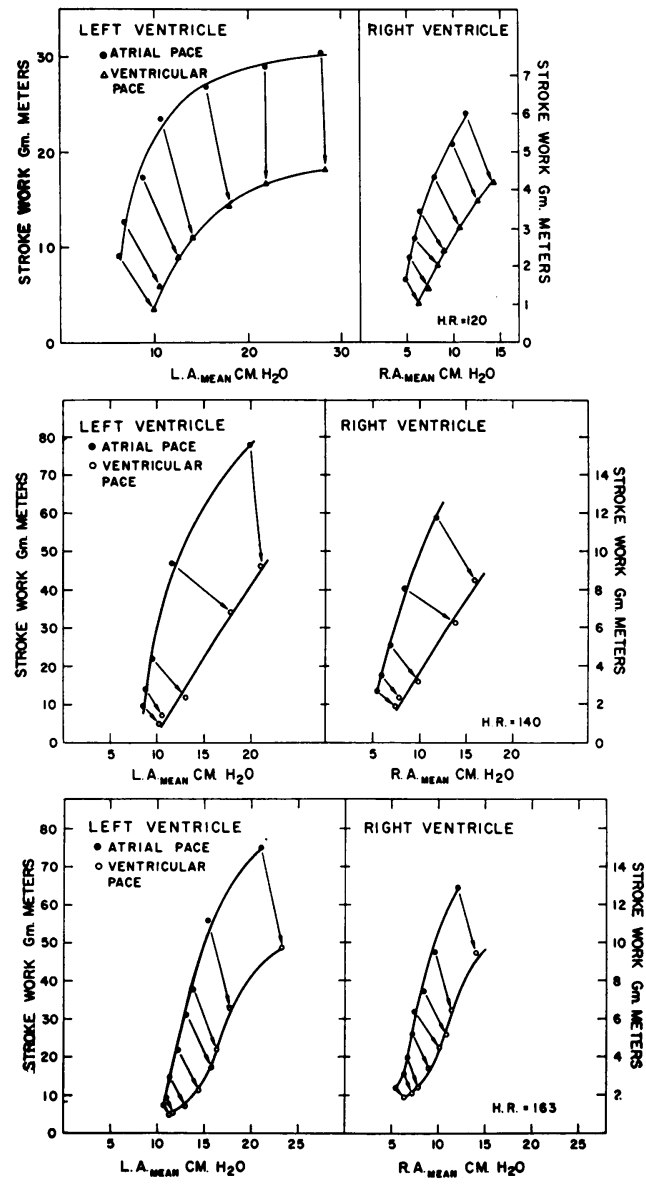

FIG. 2.-Simultaneous left and right ventricula function curves (V.F.C.LA) and V.F.C.RA) fror three experiments. In each instance the arrow indicate the change in mean atrial pressure an ventricular stroke work that took place when th stimulus was changed from atrium to ventricle H.R. = heart rate. Bilateral cervical vagotom: and left stellate ganglionectomy. 


\section{RESULTS}

Effect of Increasing Voltage on Observed Hamodynamic Values. In the earlier experiments a check was made to ascertain whether simply increasing the applied voltage would produce an alteration in the hæmodynamic variables being observed. A fivefold increase over the voltage threshold, as for example from 2 to 10 volts, did not result in observable hæmodynamic changes when the stimulus was applied either to the atrium or to the ventricle.

Effect of Changing from Atrial to Ventricular Stimulation. Fig. 1 shows data representative of the type of changes obtained in 13 dogs. When the stimulus being applied to the atrium was abruptly applied to the ventricle instead, cardiac output and aortic pressure promptly fell; a diminution in right and left ventricular stroke work occurred, and mean atrial pressures rose. These phenomena were observed when the stimulus was changed from left atrium to either left or right ventricle or from right atrium to either left or right ventricle. When the atrium was once again paced, the previous control values were restored. These phenomena were consistently reproducible in any given experiment. In the experiment shown in Fig. 1 the stellate ganglia on both sides had been removed and the vagi sectioned in the neck so as to eliminate the reflex cardiac effects that might otherwise emanate from the baroceptors when the arterial pressure is abruptly changed (Sarnoff et al., 1960b) thus making it possible to achieve the unbuffered steady state changes seen in Fig. 1.

It was noted that, when switching from atrial to ventricular pacing, the increase in mean right atrial pressure was sometimes greater than that on the left, that in the left atrium greater than that in the right, or about equal as in Fig. 1. This appeared to be related in some way to the placement of the ventricular electrode. An example of this is shown in Fig. 3. When the stimulus was switched from the right atrium to the right ventricle, left atrial pressure rose more than right atrial

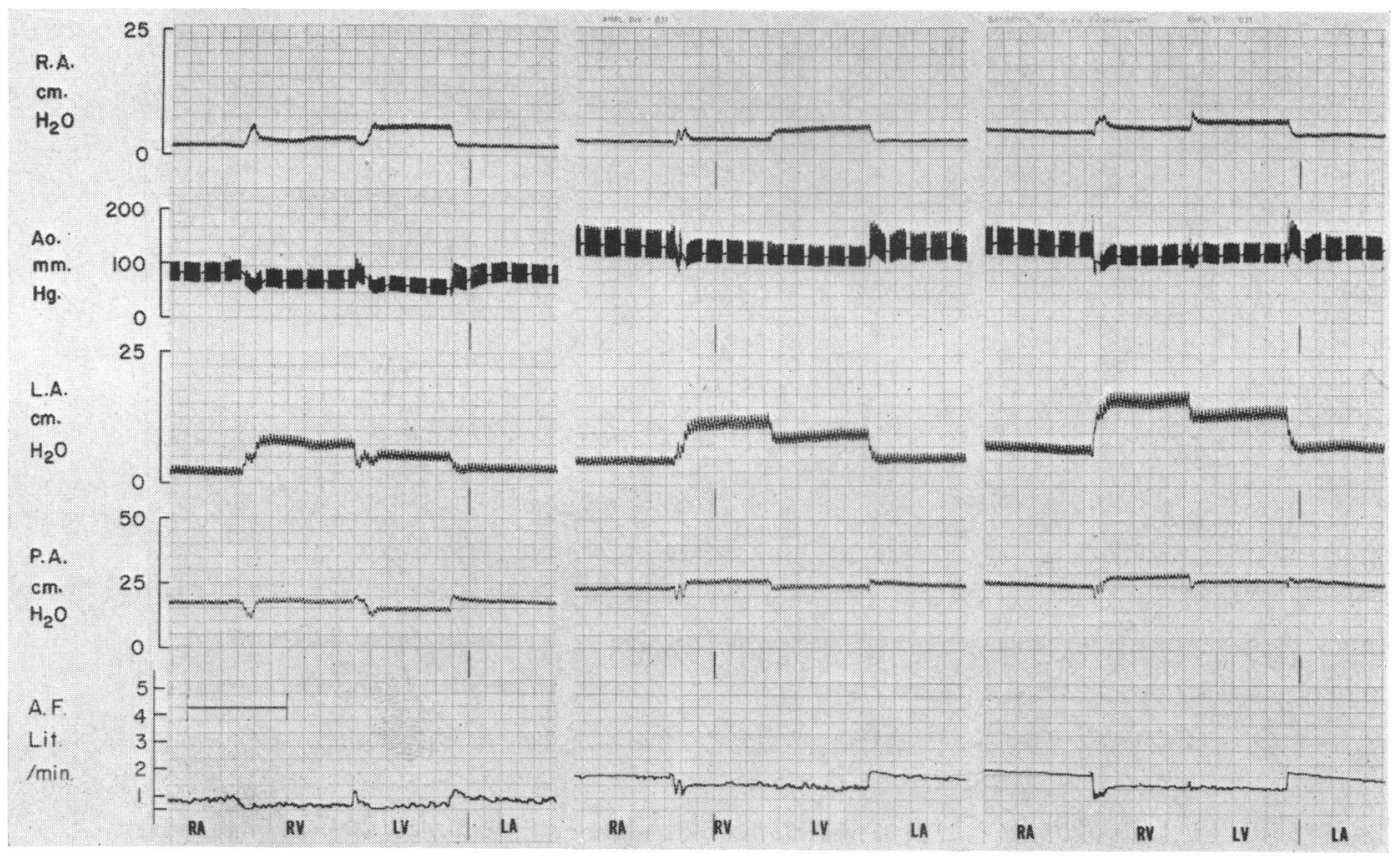

FIG. 3.-Symbols as in Fig. 1. Letters at bottom indicate periods during which the pacing stimulus was applied to the right atrium (R.A.), right ventricle (R.V.), left ventricle (L.V.), and left atrium (L.A.). An intravenous infusion of previously mixed donor blood was made between the tracings of left and middle panels and again between the tracings of the middle and right panels. Bilateral cervical vagotomy. Heart rate was 230/min. throughout. Chart speed $=0.5 \mathrm{~mm}$. $/ \mathrm{sec}$.; the bar in the lower channel of the left panel indicates an interval of one minute. 
pressure. Switching the stimulus from right ventricle to left ventricle altered this relation, causing right atrial pressure to be raised further while left atrial pressure fell from its previous value although it still remained higher than the control level obtained during right atrial pacing. The subsequent change to stimulation of the left atrium re-established the levels observed when the right atrium was paced. The same relative relations obtained at each of the three initial hæmodynamic levels examined in Fig. 3. It was of interest that, although the relative increase of left and right atrial pressures was considerably influenced when switching from right to left ventricular stim :lation, such a change did not appreciably influence cardiac output.

Effect of Ventricular Pacing on Curve Relating Mean Atrial Pressure and Ventricuiar Stroke Work. Data for ventricular function curves were gathered while stimulating the atrium, then the ventricle, and then again the atrium. After this, an infusion of previously mixed blood was given and the comparison again made. This procedure was repeated until five to eight such comparisons had been made. The curves in Fig. 2 are from three experiments in two preparations (heart rates 120,140 , and 163) and are representative of those obtained in nine such experiments. In each graph the arrow indicates the shift in values that occurred as the result of changing from atrial to ventricular stimulation.
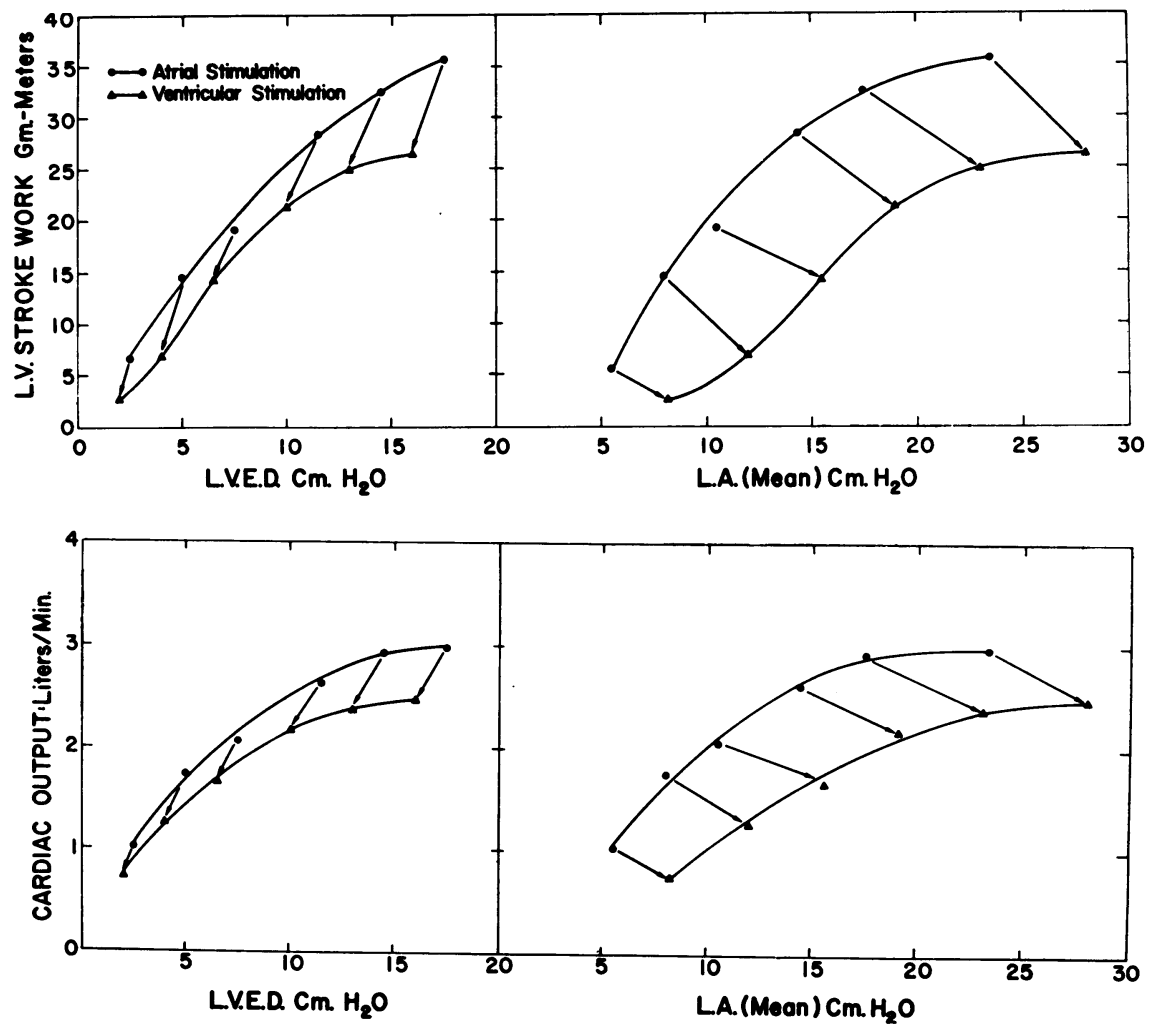

Fig. 4.-Upper. At the left is the plot of left ventricular end-diastolic pressure and left ventricular stroke work (V.F.C.Lv). At the right is the simultaneously obtained plot of mean left atrial pressure and left ventricular stroke work (V.F.C.LA). Each arrow indicates the changes in pressure and stroke work that took place when changing from atrial to ventricular stimulation.

Lower. At the left is the plot showing relation between left ventricular end-diastolic pressure and cardiac output. At the right the plot is of mean left atrial pressure and cardiac output. Same experiment as in the upper two panels. Bilateral cervical vagotomy and left stellate ganglionectomy. Heart rate $=185$. 
Relation between Left Ventricular End-diastolic Pressure and Stroke Work. Fig. 4, upper, shows the results of one of four experiments in which left ventricular end-diastolic pressure as well as left mean atrial pressure were recorded and observations made during both atrial and ventricular pacing. The curves relating either mean left atrial pressure or left ventricular end-diastolic pressure to left ventricular stroke work were both shifted to the right, the former more than the latter. In each instance, when the stimulus site was switched from atrium to ventricle, either mean left atrial pressure rose while, simultaneously, left ventricular end diastolic pressure fell (Fig. 4, upper) or mean left atrial pressure remained the same and there was a greater fall in left ventricular end-diastolic pressure. In all cases the difference between mean left atrial pressure and left ventricular end-diastolic pressure was increased. In the lower part of Fig. 4, data from the same experiment as that shown above show the relation between left ventricular end-diastolic pressure and cardiac output and the relation between mean left atrial pressure and cardiac output.

Representative high speed tracings of the type obtained in this study are shown in Fig. 5 and 6. It is clear that when the left ventricle was being paced in the manner described above, the atrium was contracting against a closed mitral valve. This resulted not only in an accentuated $a$ wave but a higher mean left atrial pressure relative to left ventricular end-diastolic pressure. Characteristic of the pulse contours observed during ventricular pacing was a much less brisk initiation of ventricular systole. The rate of development of pressure was substantially lower. This resulted in a prolonged isovolumic systolic period; and ventricular relaxation, as judged by the rate of pressure decline, was also slower. As a consequence of these phenomena, the diastolic interval was shorter and less well defined. The duration of left ventricular ejection was prolonged relative to the ejected volume, and an example of this is shown in Fig. 6. The ventricle required the same period to eject $5.8 \mathrm{ml}$. during ventricular pacing as it had required to eject $11.1 \mathrm{ml}$. during atrial pacing; whereas,

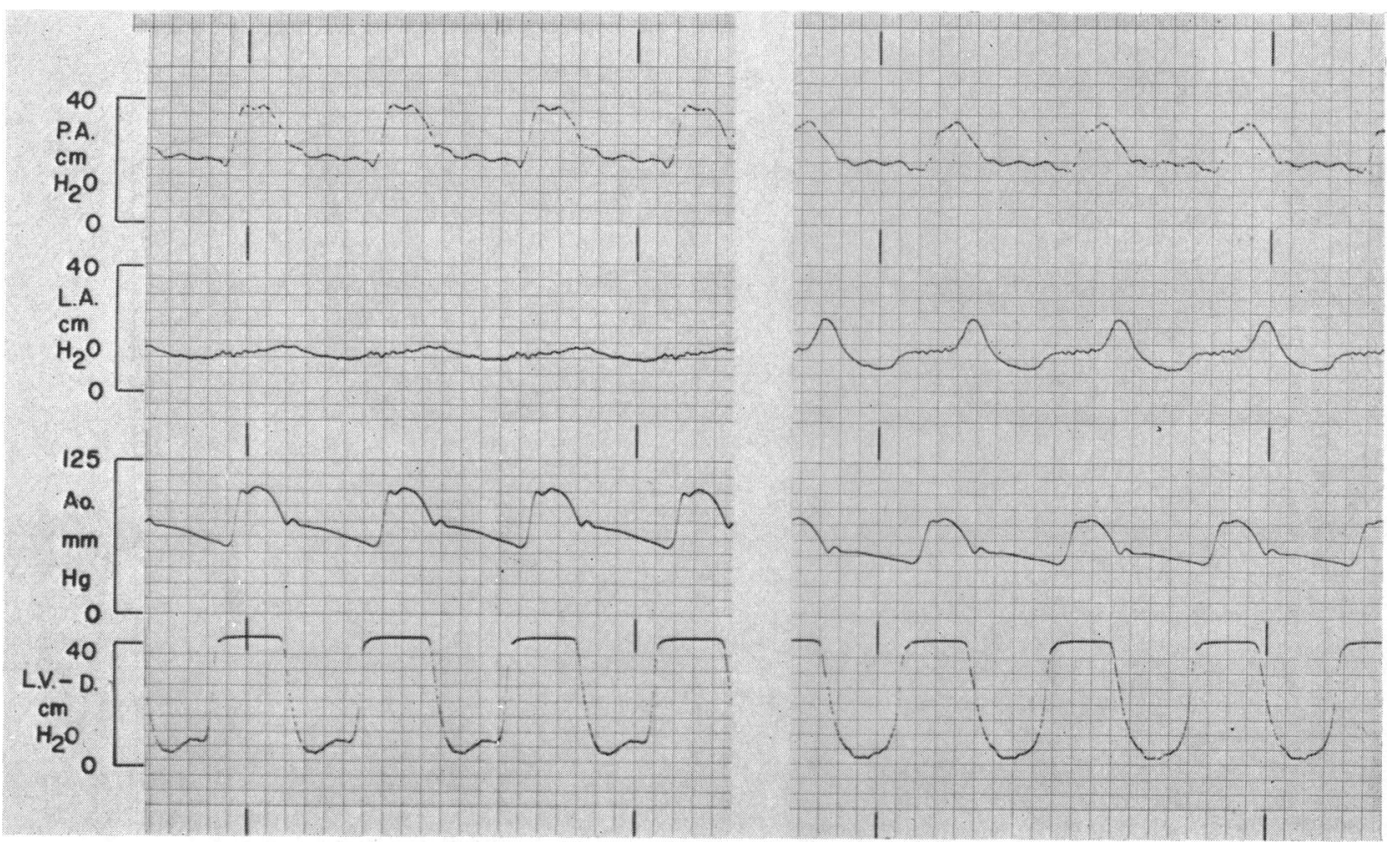

FIG. 5.-P.A.= pulmonary arterial pressure; L.A.=left atrial pressure; Ao=aortic pressure; and L.V.-D.= left ventricular diastolic pressure. Left panel taken during left atrial stimulation; right panel taken during left ventricular stimulation. Heart rate $=162$. Bilateral cervical vagotomy and left stellate ganglionectomy. Chart speed $=100 \mathrm{~mm} . / \mathrm{sec}$. 

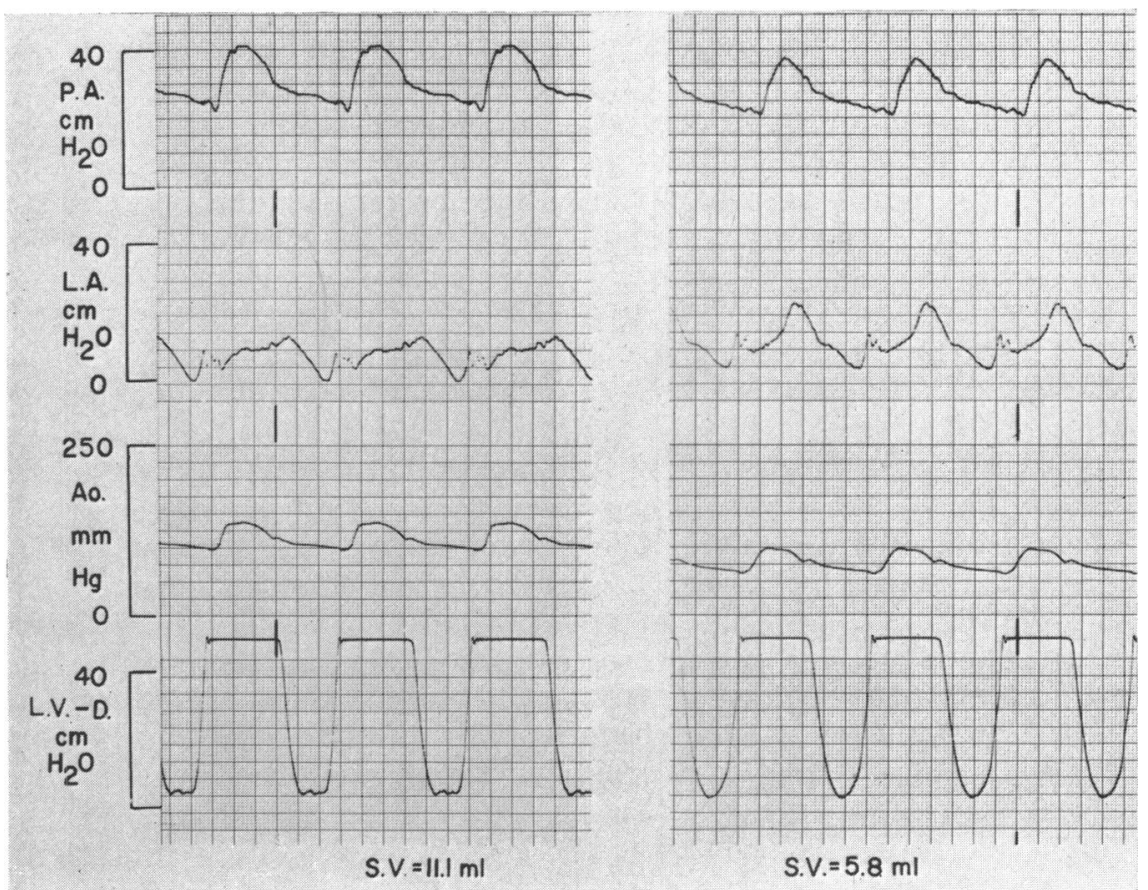

FIG. 6.-Abbreviations as in Fig. 5, and S.V.=stroke volume. Left panel taken during left atrial stimulation; right panel taken during left ventricular stimulation. Heart rate $=$ 194. Bilateral cervical vagotomy and left stellate ganglionectomy. Chart speed= $100 \mathrm{~mm} . / \mathrm{sec}$.

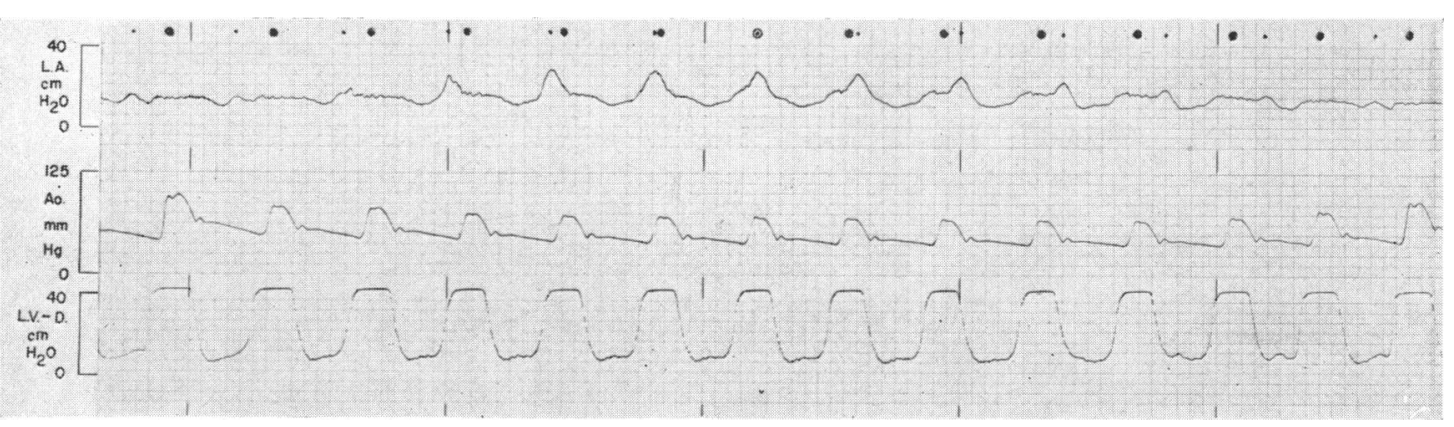

Fig. 7.-Abbreviations as in Fig. 5. Spontaneous atrial rate was $149 / \mathrm{min}$. Left ventricle paced at $161 / \mathrm{min}$. Small dot (at the top of the left atrial channel) is above left atrial systole. Large dot is placed above left ventricular systole. Full atrial eclipse in the centre (open circle around small dot). Chart speed =100 mm./sec. Bilateral cervical vagotomy and left stellate ganglionectomy.

ordinarily, a lowering of stroke volume lowers the duration of ejection (Braunwald, Sarnoff. and Stainsby, 1958; Wallace et al., 1963). Stroke work fell from $18 \cdot 3$ to 5.8 grammetres.

Of further interest in these tracings is the prolongation of the interval between the onset of left ventricular systole and the beginning of right ventricular ejection as evidenced by the beginning of the pulmonary arterial pressure rise. In Fig. 5 this interval was prolonged by $30 \mathrm{~m} \mathrm{sec}$. and in Fig. 6 by $50 \mathrm{~m}$ sec. during left ventricular pacing. An increase in the time required for total activation of the heart appeared to have taken place. 
The above changes were observed in varying degree whenever the pacing site was changed in the manner described, even when left ventricular end-diastolic pressure was re-elevated by infusion to the level that had obtained during atrial pacing.

Eclipse of Atrial Systole by Selected Ventricular Pacing. As shown in Fig. 7, it is possible to demonstrate the graded response of the ventricle when atrial systole is systematically dislocated from its proper temporal relation to the onset of ventricular systole. This was accomplished by pacing the ventricle at a rate $(161 / \mathrm{min}$.) slightly higher than the spontaneous atrial rate $(149 / \mathrm{min}$.). Atrial and ventricular systole were thus made to phase in and out of their proper temporal relation. The small dot at the top represents the peak of atrial systole; the large dot represents the time of ventricular systole. The first and last cycle in the tracing show the atrium in proper relation to ventricular systole, the atrial contribution to ventricular end-diastolic pressure, and what appears to be a properly conducted ventricular systole. The beats in the centre of the tracing show, in varying degree, the eclipse of atrial systole, the lack of an effect of atrial systole on ventricular enddiastolic pressure, atrial tracings suggestive of mitral regurgitation, and what appear to be less synchronous ventricular beats. The effect on aortic pressure is noteworthy. Attention is directed to the last four cycles during which atrial systole gradually moves forward to its proper position in diastole.

\section{Discussion}

When the ventricle contracts as the result of an electrical impulse applied directly to it rather than as the result of a normally propagated impulse, and when this takes place at such a time that the atrium is contracting against a closed mitral valve, two phenomena of note are observed. The ventricle is deprived of the benefit of the atrial contribution to ventricular filling at end diastole: this results in a shorter myocardial fibre length than would otherwise be present and a less forceful ventricular contraction thus takes place (Linden and Mitchell, 1960). Secondly, the contour of the ventricular pressure curve, examined at high resolution in its lower portions, indicates that the ventricle contracts less synchronously as evidenced by the less rapid development of and subsequent decline in its pressure. These observations are consonant with the findings that indicate that the conduction velocity in the bundle of His is substantially faster than that in non-specialized conducting tissue (Hoffman et al., 1959), with the study of Scher and Young (1955) who compared the wave of depolarization observed during normal impulse propagation with that observed during ventricular excitation, and with the observations of Boineau, Spach, and Harris (1960) who found the QRS to be prolonged during ventricular pacing especially if the pacing site was at some distance from the septum.

The assumption implicit in the analysis of the data and studies cited above is that when conduction is abnormal the hæmodynamic character of ventricular systole will be altered. If this be so, then varying the conduction pathway by varying the site of ventricular pacing should alter the ventricular tracing. Wiggers' studies, although not performed under controlled hæmodynamic conditions, nevertheless support this assumption. Other similar relevant observations are those of Meijler, Wieberdink, and Durrer (1962).

It was of interest to observe that the left ventricle produced less stroke work from any given left ventricular end-diastolic pressure during ventricular stimulation. Unlike a piston pump in which the positive stroke produces an elevated pressure in a rigid housing, pressure in the heart is produced by the sequential and progressive development of tension in the various segments of myocardium that comprise the pump chamber. When these segments contract independently of any programmed sequence, no external work at all is accomplished, as during ventricular fibrillation. From the above data, it appears that the extent to which the myocardial fibres contract synchronously, and therefore in a briefer period, can influence the external work produced when the other factors influencing contraction are held constant. This presumably results from the extent to which there are fewer relaxed segments when contraction of any other portion of the ventricular myocardium is taking place. It follows that a greater force of contraction from an increased fibre length 
would be required to produce the same external work when a ventricular contraction is less synchronous than when it is relatively more so.

Two other aspects of the altered ventricular dynamics must be considered in evaluating the phenomena observed when changing from atrial to ventricular pacing. The first is the possibility that the lower aortic pressure obtaining during ventricular pacing diminishes ventricular contractility through the mechanism of homeometric autoregulation (Sarnoff et al., 1960c). That this does not completely account for the observed phenomena is indicated by the type of data seen in Fig. 1: a substantial immediate fall in stroke work takes place when changing to ventricular pace. Further, in recent studies on factors influencing the mean rate of ejection (Mitchell, Wallace, and Skinner, 1962), it was shown that a substantially higher left ventricular end-diastolic pressure was required to produce the same stroke work during ventricular pacing even when aortic pressure, stroke volume, and heart rate were held constant, a finding consonant with the ventricular function curve data presented above.

Secondly, it has been shown that a properly placed atrial systole can show its influence, whether or not the mitral valve is closed before the onset of ventricular systole (Little, Hilton and Schaefer, 1954; Sarnoff, Gilmore and Mitchell, 1962; and Skinner, Mitchell and Wallace, 1962). During ventricular pacing, as conducted in these experiments, atrial systole was not properly placed (Fig. 5). The question therefore arises as to whether or not a certain degree of mitral regurgitation during ventricular pacing contributed to the dimunition of ventricular function as measured by forward stroke work. The atrial pulse contour shown in Fig. 5 suggests mitral regurgitation in some instances. In other instances, the diminution in forward stroke work occurs without evidence of reflux into the atrium as shown in Fig. 6.

The data presented in this study, wherein the observed changes were induced without altering the catecholamine background, suggest the extent to which influences that alter synchronicity can modify the external stroke work and stroke power produced from any given end-diastolic pressure. If this explanation is correct, these data may aid in the interpretation of the altered ventricular dynamics observed when sympathetic stimulation is applied. For, when cardiac sympathetic stimulation results in more external stroke work and power being produced from any given end-diastolic pressure or fibre length, and the rise and fall of ventricular pressure are steeper, the ventricular contraction gives every appearance of being a more synchronous one. It may, therefore, be unwise to consider the altered performance as being due solely to the increased contractility of each fibre without considering the possibility of a more synchronous activation during sympathetic stimulation.

\section{SUMMARY AND CONCLUSIONS}

When the atrium and ventricle contract at or about the same time instead of sequentially, the ventricle is deprived of the atrial contribution to ventricular filling, mean atrial pressure rises in relation to left ventricular end-diastolic pressure, the end-diastolic pressure is lower, and the ventricle produces less external work.

Further, when the ventricle is caused to contract as the result of direct electrical excitation instead of a normally propagated impulse, it will produce less external work from any given end-diastolic pressure. Hæmodynamic evidence suggests that this is due, at least in part, to a less synchronous ventricular contraction.

The authors acknowledge the valuable technical assistance of Mr. Frank Perry, Mrs. Carrie Scott, and Mr. Eugene Purcell.

\section{REFERENCES}

Boineau, J. P., Spach, M. S., and Harris, J. S. (1960). Study of premature systoles of the canine heart by means of the spatial vectorcardiogram. Amer. Heart J., 60, 924.

Braunwald, E., Sarnoff, S. J., and Stainsby, W. N. (1958). Determinants of duration and mean rate of ventricular ejection. Circulat. Res., 6, 319.

Hoffman, B. F., Cranefield, P. F., Stuckey, J. H., Amer, N. S., Cappelletti, R., and Domingo, R. T. (1959). Direct measurement of conduction velocity in in situ specialized conducting system of mammalian heart. Proc. Soc. exp. Biol. (N.Y.), 102, 55. 
Koch, E. (1920). Der Kontraktionsablauf an der Kammer des Froschherzens und die Form der entsprechenden Suspensionskurve, mit besonderen Ausführungen über das-Alles-oder-nichts-Gesetz, die Extrasystole und den Herzalternans. Pflügers Arch. ges. Physiol., 181, 106.

Linden, R. J., and Mitchell, J. H. (1960). Relation between left ventricular diastolic pressure and myocardial segment length and observations on the contribution of atrial systole. Circulat. Res., 8, 1092. , Gilmore, J. P., Brockman, S. K., and Sarnoff, S. J. (1959). Hemodynamic changes induced by ventricular stimulation. Fed. Proc., 18, 93.

Little, R. C., Hilton, J. G., and Schaefer, R. D. (1954). The first heart sound in normal and ectopic ventricular contractions. Circulat. Res., 2, 48.

Meijler, F. L., Wieberdink, J., and Durrer, D. (1962). L'importance de la position des électrodes stimulatrices au cours du traitement d'un bloc auriculo-ventriculaire postopératif total. Arch. Mal. Caur, 55, 690.

Mitchell, J. H., Wallace, A. G., and Skinner, N. S., Jr. (1962). Factors influencing the relation between the enddiastolic pressure and mean rate of ejection of the left ventricle. Clin. Res., 10, 177.

Sarnoff, S. J., Brockman, S. K., Gilmore, J. P., Linden, R. J., and Mitchell, H. J. (1960a). Regulation of ventricular contraction: influence of cardiac sympathetic and vagal nerve stimulation on atrial and ventricular dynamics. Circulat. Res., 8, 1108.

—, Gilmore, J. P., Brockman, S. K., Mitchell, J. H., and Linden, R. J. (1960b). Regulation of ventricular contraction by the carotid sinus: its effect on atrial and ventricular dynamics. Circulat. Res., 8, 1123.

,-- , and Mitchell, J. H. (1962). Influence of atrial contraction and relaxation on closure of mitral valve: observations on effects of autonomic nerve activity. Circulat. Res., 11, 26.

- and Mitchell, J. H. (1961). The regulation of the performance of the heart. Amer. J. Med., $30,747$.

,-- , Gilmore, J. P., and Remensnyder, J. P. (1960c). Homeometric autoregulation in the heart. Circulat. Res., 8, 1077.

Scher, A. M., and Young, A. C. (1955). Spread of excitation during premature ventricular systoles. Circulat. Res., $3,535$.

Skinner, N. S., Jr., Mitchell, J. H., and Wallace, A. G. (1962). Hemodynamic effects of altering the placement of atrial systole. Clin. Res., 10, 180.

Wallace, A. G., Mitchell, J. H., Skinner, N. S., Jr., and Sarnoff, S. J. (1963). Hemodynamic determinants of the durations of the phases of systole. Circulat. Res. In the press.

Wiggers, C. J. (1925). The muscular reactions of the mammalian ventricles to artificial surface stimuli. Amer. $J$. Physiol., 73, 346. 